\title{
Review Article \\ Innovative Thoughts on Treating Diabetes from the Perspective of Traditional Chinese Medicine
}

\author{
Bing Pang, ${ }^{1}$ Qiang Zhou, ${ }^{2}$ Tian-Yu Zhao, ${ }^{1}$ Li-Sha He, ${ }^{1}$ Jing Guo, \\ Hong-Dong Chen, ${ }^{1}$ Lin-Hua Zhao, ${ }^{3}$ and Xiao-Lin Tong ${ }^{1}$ \\ ${ }^{1}$ Department of Endocrinology, Guang'anmen Hospital of China Academy of Chinese Medical Sciences, Beijing 100054, China \\ ${ }^{2}$ Department of Digestion, Beijing Hospital of Traditional Chinese Medicine, Capital University of Medicine Sciences, \\ Beijing 100010, China \\ ${ }^{3}$ Laboratory of Molecular Biology, Guanganmen Hospital of China Academy of Chinese Medical Sciences, Beijing 100054, China
}

Correspondence should be addressed to Lin-Hua Zhao; melonzhao@163.com and Xiao-Lin Tong; xiaolintong66@sina.com

Received 24 November 2014; Accepted 10 April 2015

Academic Editor: Musa Toyin Yakubu

Copyright (C) 2015 Bing Pang et al. This is an open access article distributed under the Creative Commons Attribution License, which permits unrestricted use, distribution, and reproduction in any medium, provided the original work is properly cited.

\begin{abstract}
The rapidly increasing incidence of diabetes mellitus (DM) is becoming a major public health issue. As one of the important parts in complementary and alternative therapies, traditional Chinese medicine (TCM) is promising in treating DM. In this review, we summarize new thoughts on treating DM that aim to improve the clinical efficacy of TCM from the perspectives of principle, methods, formula, herbs, and doses. Our approach is as follows: principle: we use a combination of symptoms, syndromes, and diseases as a new mode for treating diabetes; methods: emphasizing heat-clearing in the early and middle stage of T2DM and invigorating blood circulation throughout the whole process of T2DM are two innovative methods to treat T2DM; formulas and herbs: choosing formulas and herbs based on the combination of TCM theory and current medicine. We will emphasize four strategies to help doctors choose formulas and herbs, including treatment based on syndrome differentiation, choosing herbs of bitter and sour flavors to counteract sweet flavor, choosing formulas and herbs aimed at main symptoms, and using modern pharmacological achievements in clinical practice; dose: reasonable drug dose plays an important role in the treatment of DM and a close relationship exists between dose and clinical efficacy.
\end{abstract}

\section{Introduction}

Diabetes mellitus (DM) is a chronic metabolic disorder caused by either absolute deficiency in insulin secretion or reduction in the biological effectiveness of insulin. The global prevalence of DM among adults aged 20-79 years was $8.3 \%$ in 2013 [1]. As one of the largest developing countries, China has the biggest population of patients with DM with 92.4 million, which account for $9.7 \%$ of the adult population. In addition, 148.2 million adults (15.5\%) have prediabetes [2]. $\mathrm{DM}$ has a significant impact on the quality of life and life expectancy of people as well as on the economic burden on the health care system. Therefore, it represents a major public health issue [3]. Type 2 diabetes mellitus (T2DM) is the predominant form of DM and accounts for $90-95 \%$ of the diabetic populations, due to an increased number of elderly patients and a greater prevalence of obesity and sedentary lifestyles $[4,5]$. Management of T2DM is still a challenge and the standard therapy for T2DM includes balanced diet, appropriate exercise, use of oral hypoglycemic drugs, and/or subcutaneous insulin injections [6]. Although considerable progress has been made regarding hypoglycemic drugs and insulin, Western medicine still has some limitations. Traditional Chinese medicine (TCM) has a long history of more than 2000 years in treating DM [7, 8], and there are several advantages in treating DM with TCM, including lower rate of toxicity and/or side effects, holistic regulation of metabolic problems, reversal of risk factors leading to T2DM, and delaying diabetic complications. Due to the differences in etiology, pathogenesis, diagnosis, and interventions between traditional Xiaoke disease and T2DM, several new therapeutic thoughts have been recently proposed. In this review, we summarized these thoughts based on principle, method, formula, herbs, and dose through literature analysis in both 


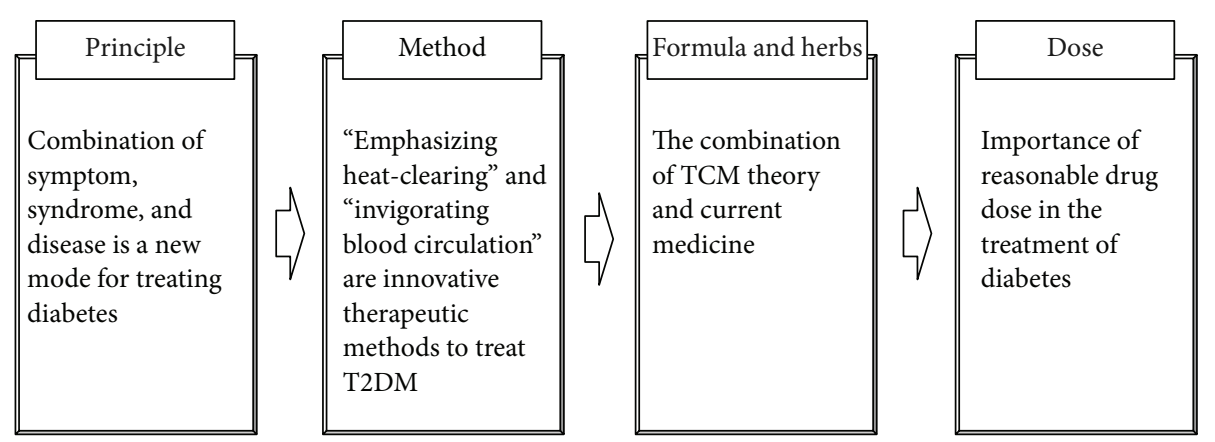

FIGURE 1: The scheme figure of the innovative thoughts in the treatment of diabetes.

English and Chinese search engines to guide clinicians in treating T2DM. The scheme figure of the innovative thoughts in the treatment of diabetes is shown in Figure 1.

\section{Principle: Combination of Symptom, Syndrome, and Disease Is a New Mode for Treating Diabetes}

The "combination of symptoms, syndrome, and disease" has been widely used in the treatment of several chronic difficult diseases [9-11]. The mode of combining symptoms, syndromes, and diseases is shown in Figure 2. Syndromes, also known as "zheng" or "pattern," are the abstraction and generalization of the pathological changes at a certain stage of a disease, which shows the essence of a disease more deeply and completely [12]. Syndrome differentiation is diagnosed through comprehensive consideration of symptoms and signs (tongue appearance and pulse feeling included) and has implications for determining the cause, location, and nature of the disease and the patient's physical condition, as well as the trend of development [13]. As an example for syndrome differentiation, one T2DM patient with obesity, reddened complexion, stuffiness and fullness in the abdomen, red tongue, yellow-greasy coating, and slippery pulse may suffer from typical phlegm and heat stasis syndrome, while the other T2DM patient may suffer from losing weight, fatigue, excessive sweating, dry mouth, insomnia, red tongue, thin coating, and vacuous and rapid pulse and may be differentiated with the syndrome of dual deficiency of qi and yin. The condition was specific to the individual and appropriate treatment was suggested. Syndrome differentiation is the most remarkable characteristic in TCM, and all diagnostic and therapeutic methods of TCM are derived from this principle.

However, syndrome differentiation has several limitations. It regulates the patient's physical condition with a holistic approach to health, but the need to relieve the patient's most painful symptoms is not met in the short term. Moreover, several diseases are found before the appearance of signs and symptoms, which leads to "no syndrome may differentiate." According to these reasons, more attention should be paid to alleviate the main symptoms. A symptom is a characteristic sign of a particular disease and is a (bodily or mental) phenomenon, circumstance, or change in condition arising from and accompanying a disease or another pathological condition [14], which includes the subjective perception of patients, as well as objective indicators of diseases obtained from testing methods. In ancient China, physicians treated diseases mainly by directly improving symptoms. Some herbal classics described herb efficacies by alleviating the main symptoms; for example, Chuanwu (Radix Aconiti Praeparata) may alleviate pain, Banxia (Rhizoma Pinelliae) may alleviate nausea and vomiting, Walengzi (Concha Arcae) may relieve gastric hyperacidity, and so on. There are several advantages in aiming at main symptoms. First, it is an effective way to relieve the most painful symptoms directly. For example, some diabetic patients also have erectile dysfunction (ED), which may be the most painful symptoms to male patients. Chuanxiong (Rhizoma Chuanxiong) and Wugong (Scolopendra) were first considered to improve this symptom directly, and subsequently other formulas and herbs were added to constitute a complete prescription. Secondly, difficult diseases always have a complicated etiology and pathogenesis, which results in difficulties with syndrome differentiation; "treating aimed at main symptoms" has the advantage of simplifying the differentiated process and reversing the trends of acute disease directly, thus achieving great clinical efficacy. Thirdly, it could solve the problem of "no syndrome may differentiate"; patients who did not show obvious symptoms in the clinic were found to have abnormal blood lipid indicators and can be treated with herbs such as Shanzha (Fructus Crataegi), Hongqu (Red konjac powder), and Wuguchong (Oriental latrine fly larvina) aimed at hyperlipidemia.

As mentioned above, the characteristics of a syndrome are relatively widespread and abstract, which is easy to conceal the difference [9-11]. The following example may help to explain the shortage of syndrome differentiation. Tuberculosis, lung cancer, diabetes, and chronic nephritis all have a similar syndrome of dual deficiency of qi and yin, but the pathogenesis and prognosis of the above diseases are different, thereby indicating that they should be treated with the same TCM method of boosting qi and nourishing yin; however, this treatment may have insufficient effects on the diseases. This is why syndrome differentiation has strong effects on improving the syndrome but poor effects on treating diseases. Thus, more attention has to be paid to treating diseases. A disease is a condition of poor (more or 


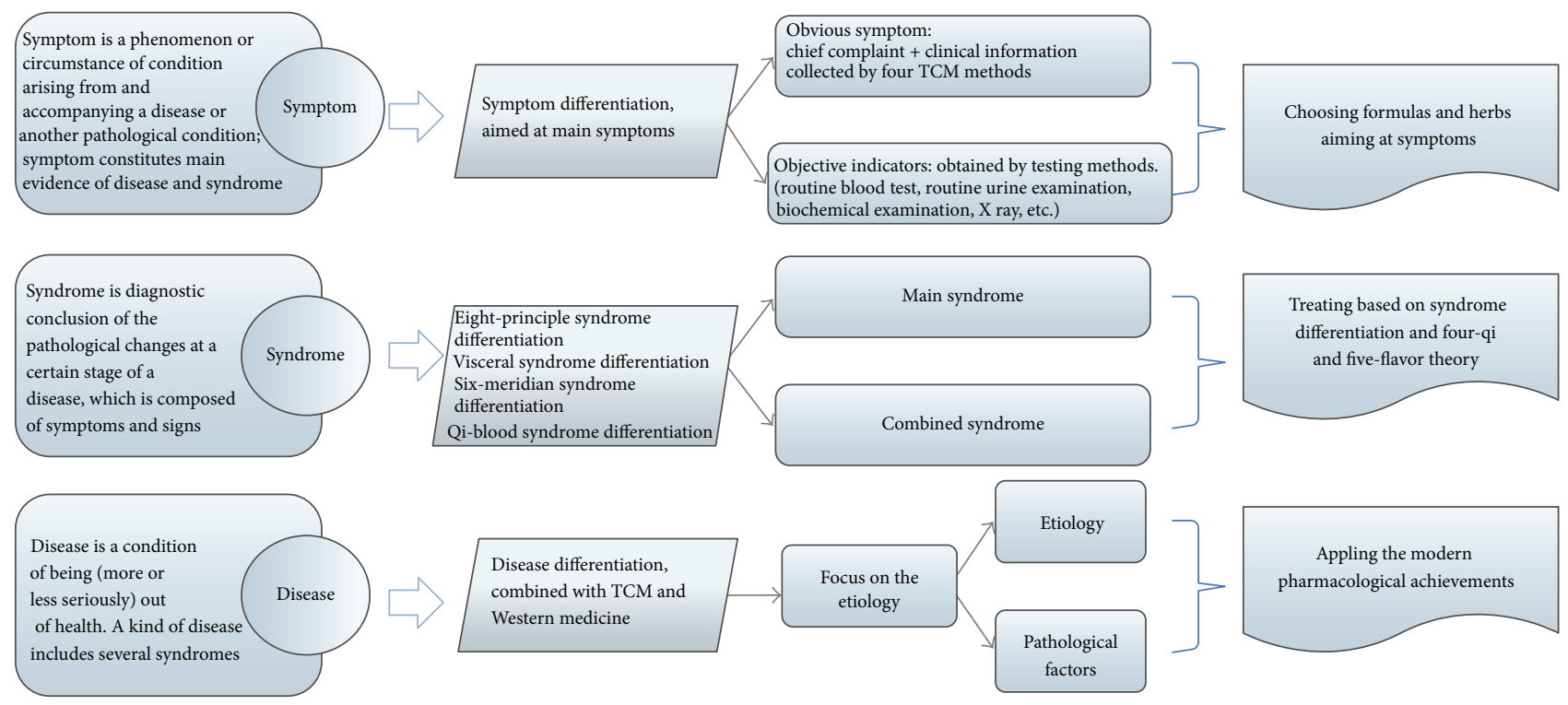

FIGURE 2: The mode of combining symptom, syndrome, and disease.

less seriously) health [9-11]. Disease differentiation provides the main direction for treatment and improves the specificity of the treatment. A lot of the attention should be paid to pathological characteristics of the disease as well as objective indicators such as X-rays and ultra sound. For example, when diabetes, lung cancer, and tuberculosis were found to have similar syndrome of dual deficiency of qi and yin, based on the principle of boosting qi and nourishing yin, the treatment of diabetes may lower the blood glucose, while the treatment for lung cancer may help fight the tumor, and the treatment in tuberculosis is for eliminating M. tuberculosis.

Currently, the combination of symptoms, syndromes, and diseases has become a common mode in the diagnosis and treatment of TCM [9-11], which focuses on "treating aimed at main symptoms directly," "highlighting chemical or biochemical indicators," "choosing the formulas that treat both TCM syndromes and diseases in Western medicine," "emphasizing etiology, pathogenesis, and diagnosis of diseases in Western medicine," and so on. It is an important way for TCM merging with modern clinical treatment. The following example may help to understand the mode of combination of symptoms, syndromes, and diseases, and the details are in Figure 3.

\section{Method: Two Important and Innovative Therapeutic Methods}

3.1. Differences Exist between Modern Clinical Features of T2DM and the "Three Excess and One Loss" of Traditional Xiaoke Disease. In traditional Chinese medicine (TCM), DM may fall under the categories of "Xiaoke disease" and others. It is characterized by excessive drinking, excessive food consumption, excessive urination, and weight loss. All of these symptoms are commonly referred to as "three excess and one loss." The main pathogenesis lies in yin deficiency leading to endogenous dryness-heat in the body, and blood stasis and phlegm retention are often present. If prolonged yin deficiency impairs yang, dual deficiency of qi and yin as well as dual deficiency of yin and yang will occur. Therefore, the main TCM therapeutic methods for Xiaoke disease are invigorating qi, nourishing yin, clearing away the heat, and promoting fluid production $[3,15,16]$. Famous formulas including Yuye Tang, Bai Hu Jia Renshen Tang, and Jin Gui Shen Qi Wan are widely used $[3,4,15,16]$. In recent years, several studies have also demonstrated that the distinctive symptoms of T2DM are the "three excess and one loss" [17]. However, modern clinics have found several new features of patients with T2DM, which are as follows. First, 50\% of patients with T2DM are without any symptoms, while the diabetic symptoms are not typical in $80 \%$ of patients [18]. Clark et al. [19] showed that patients who controlled the blood glucose poorly presented with diabetic symptoms that are defined by the American Diabetes Association (ADA), while patients who controlled their blood glucose well during the early stage of T2DM had no symptoms. Su and Yang [20] proposed that the symptoms of "three excess and one loss" were only manifested in patients with moderate to severe degrees of T2DM. In ancient times, the diagnosis of Xiaoke disease was primarily based on the symptoms of patients, Xiaoke disease could only be diagnosed when these distinctive symptoms appeared, and there was no intervention with Western hypoglycemic drugs. Nowadays, it is often physical examination that leads to the diagnosis of T2DM before the appearance of the "three excess and one loss," even in prediabetes. The examination of blood glucose is convenient and easy. The early interventions by Western hypoglycemic drugs are common, and the therapeutic methods achieve continuous optimization. Secondly, overweight or obese patients are the main population that suffers from T2DM. In European and American countries, approximately 


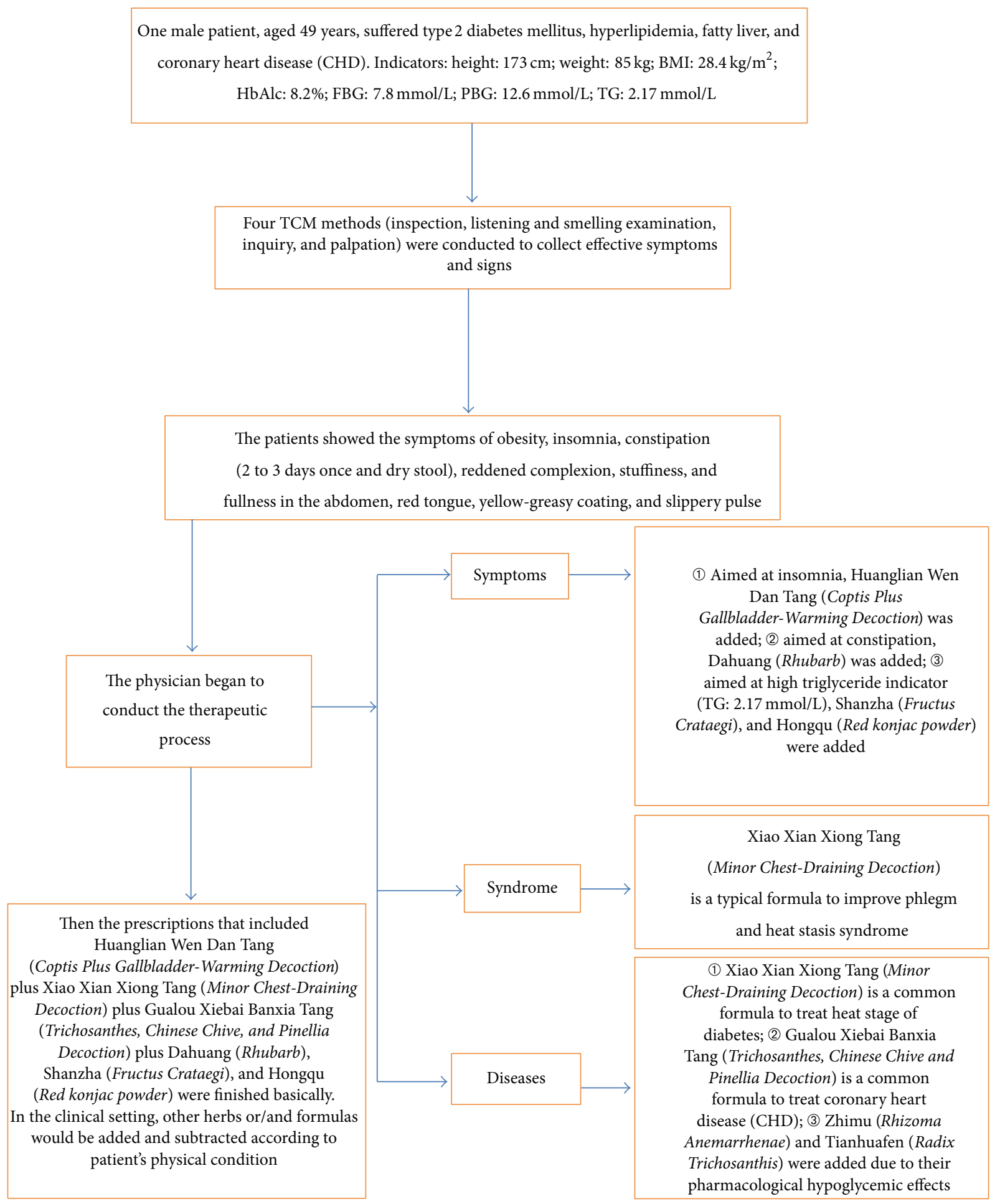

FIgURE 3: The clinical application of the new mode.

$85 \%$ of T2DM patients are overweight or obese, and only $15 \%$ of them are normal or thin [21], which is similar to the situation in China. Sixty percent of patients with T2DM also have dyslipidemia. Hyperglycemia, hyperlipidemia, obesity, and fatty liver always occur in combination and cause diseases. Thirdly, patients with the sthenia syndrome outnumber the cases with asthenia syndromes, and internal heat is the core pathogenesis of obese T2DM in the early and middle stages of T2DM $[8,22,23]$. Due to the changes in the etiology, pathogenesis, diagnosis, and interventions between traditional Xiaoke disease and T2DM, new therapeutic methods have been proposed to adapt to the clinical need. 
3.2. Emphasizing Heat-Clearing in the Early and Middle Stages of T2DM. According to the above, the basic pathogenesis in the early and middle stages of T2DM is associated with "heat"; some scholars have also proposed a concept of "toxin," such as "glucose toxin" (too much sugar), "lipid toxin" (too much fat), or too many "inflammatory actors," which refers to the excessive harmful substances in the body of type 2 diabetic patients due to overintake of sweet and greasy food [24, 25]; therefore, "heat" and "toxin" are considered important factors leading to DM. Huang Lian (Rhizoma Coptidis) is the classical heat-clearing and detoxifying herb for DM, and berberine (BBR) is an important active component of Huang Lian [26]. Yin et al. [27] investigated the clinical efficacy and safety of BBR in a pilot study. Thirty-six adults with newly diagnosed T2DM were randomly assigned to BBR or metformin treatment $(500 \mathrm{mg}$ three times a day) in a 3-month study. Results showed that BBR significantly lowered hemoglobin Alc (HbAlC), fasting blood glucose (FBG), postload plasma glucose (PBG), and TG in patients with T2DM $(P<0.05$ or $P<0.01)$. Forty-eight adults with poorly controlled T2DM were treated with supplemental BBR for 3 months in a second study. There was a significant decrease in the level of blood glucose and lipids, indicating that the hypoglycemic effect of BBR was similar to that of metformin. Green tea has the property of cold and lowers the fire [28], and some studies have provided evidence that drinking tea could improve insulin resistance and ameliorate the potential risk for T2DM $[29,30]$. Current medicine has generally accepted that DM is usually associated with chronic subclinical inflammation [31]. The role of inflammation in the pathogenesis of T2DM and its vascular complications has been confirmed by several studies [32]. Traditional Chinese herbs and formulas usually exert the hypoglycemic effects by controlling inflammation; some heat-clearing and detoxifying herbs and formulas especially possess anti-inflammatory effects. Many studies have shown that heat-clearing herbs could control the blood glucose by inhibiting inflammation, such as Huang Lian (Rhizoma Coptidis), GeGen (Radix Puerariae), ZhiMu (Rhizoma Anemarrhenae), and Tian Hua Fen (Radix Trichosanthis) [4, 32]. Huang-Lian-Jie-Du-Tang (HLJDT) is the classical heatclearing and detoxifying formula used for diabetes [33]. Current medicine has shown that it exhibits anti-inflammatory effects in BALB/c mice and carrageenan-induced mice by inhibiting the production or expression of malondialdehyde (MDA), superoxide dismutase (SOD), nitric oxide (NO), prostaglandin E (2) (PGE2), tumor necrosis factor- $\alpha$ (TNF$\alpha$ ), and interleukin-6 (IL-6) to lower the blood glucose [3437]. The method of "Kaiyu Qingre (dissipate stagnation of qi and clear away the heat)" has been proposed according to evidence-based medicine; in one research on observing the Chinese herbal medicine on obese type 2 diabetic patients, Kaiyu Qingre Jiangzhuo formula (KQJF) was given to the treatment group, while metformin was given to the control group. The results showed that there was no significant difference statistically between two groups on lowering the blood glucose $(P>0.05)$ [38]. It is the first evidence of Chinese herbal medicine on lowering the blood glucose in the clinic [8].
3.3. Invigorating Blood Circulation throughout the Entire T2DM Process. There are different degrees of vascular lesions in $50 \%$ of patients with newly diagnosed T2DM, although some patients' symptoms are atypical [39]. T2DM subclinical vascular lesions are caused by abnormal glycolipid metabolism, oxidative stress, inflammatory factors, insulin resistance, and so on, which exist throughout the entire T2DM process and gradually lead to diabetic complications. Complicated lesions may involve many organs, such as heart, brain, kidneys, retina, nervous system, and skin [40]. Vascular lesions may be considered collateral damage in TCM; the pathogenesis of collateral damage changes from collateral qi stagnation to collateral blood stasis, then to collateral blockage, and finally to collateral damage [41-43]. Sublingual collateral vessels are generally observed to determine the degree of collateral damage, and the observation includes the following two aspects: the body and the color of collateral vessels [42]. Treatment should be aimed at improving the blood circulation and removing obstruction in vessels [41, 42]. Luotong (modified Di Dang Tang, mainly composed of Dahuang (Rhubarb), Shuizhi (Hirudo), and Taoren (Semen Persicae)) is widely applied to activate blood and unblock the collaterals. In the clinical setting, combined therapies of hypoglycemia and Luotong could slow down the progression from impaired glucose tolerance (IGT) to diabetes [42]. Tang-Luo-Ning (TLN, mainly composed of Huangqi (Radix Astragali), Danshen (Radix et Rhizoma Salviae Miltiorrhizae), and Chishao (Radix Paeoniae Rubra)) is used to activate blood and unblock the collaterals. Animal experiments have shown that treatment with TLN may be helpful in delaying the progression of diabetic peripheral neuropathy (DPN) by exerting a neural protection effect [44]. Tong Xin Luo (TXL) has been used in patients with diabetic nephropathy (DN) and has been registered in the State Food and Drug Administration of China. TXL showed positive effects on decreasing the 24-hour urine albumin excretion ratio $(24 \mathrm{~h}$ UAER) and blood urea nitrogen (BUN). In the treatment of early DN, TXL could improve renal microcirculation, reduce Cys-C and UAER, and delay the progression of renal damage. The mechanism may be related to inhibition of TGF- $\beta 1$ induced epithelial-to-mesenchymal transition in DN [45]. A type of aqueous extract of Huangqi (Radix Astragali), Danggui (Angelica sinensis), and Sanqi (Panax notoginseng) with the therapeutic efficacy of nourishing the blood and invigorating the blood is effective in preventing diabetic retinopathy (DR) by inhibiting leukocyte adherent to the vascular wall, attenuated vascular leakage, and formation of acellular capillaries [46].

\section{Formula and Herbs: The Combination of TCM Theory and Current Medicine}

4.1. Treatment Based on Syndrome Differentiation. The first guideline for DM was published in 2007, named Guideline of Prevention and Treatment of Diabetes by TCM. With the unification of TCM terminology, diabetes-related terminology became gradually normalized and standardized [8]. Generally speaking, the stagnation stage that represents 
the body is in a state of congestion and stagnation during the early period of DM, which could be differentiated into syndromes of qi stagnation due to liver depression and spleen and stomach congestion. Xiaoyao Powder or Houpo Sanwu Tang is recommended to dissipate the stagnation and remove the congestion. The heat stage represents the development of diseases and could be seen more as the sthenia syndrome during the early or middle periods of T2DM. Based on the comprehensive and systemic review, peer review, validation sessions, and analysis of literature, the TCM clinical guidelines were finally formulated, and the heat stage was differentiated into six common clinical syndromes. Heat-clearing and fire-draining are important therapeutic methods. Da Chaihu Tang is commonly recommended for liver and stomach stagnated heat syndromes, Bai $\mathrm{Hu}$ Tang for lung and stomach exuberant heat syndromes, Dahuang Huanglian Xie Xin Tang for stomach and intestine excessive heat syndromes, Gegen Qin Lian Tang for intestinal damp and heat syndromes, Xiao Xian Xiong Tang for phlegm and heat stasis syndromes, and San Huang Tang plus Wu Wei Xiao Du Yin for intense heat toxin syndrome. The deficiency stage represents the further development of the disease and could be seen in more syndromes of asthenia and sthenia in complex middle or late periods of diabetes. The deficiency stage can be differentiated into five syndromes, including deficiency of body liquid due to excessive heat, effulgent fire due to yin deficiency, dual deficiency of qi and yin, spleen deficiency and stomach congestion, and cold and heat in complexity. The key points of treatment in this stage are supplementing the deficiency and eliminating the excess. Bai Hu Jia Renshen Tang, Zhi Bai Dihuang Wan, Sheng Mai Yin plus Zeng Ye Tang, Banxia Xie Xin Tang, or Wumei Wan is recommended. The damage stage represents the end of the disease. At this stage, the functions of the zang$f u$ organs become gradually weaker, and some pathological factors accumulate, such as phlegm, turbid, stasis, or toxin. The treatment should be based on regulating yin and yang. The damage stage could be differentiated into liver-kidney yin deficiency, dual deficiency of yin and yang, and spleen-kidney yang deficiency syndromes. Qi Ju Dihuang Wan, Jin Gui Shen Qi Wan, and Fuzi Li Zhong Wan are commonly used [22]. The details are shown in Table 1.

4.2. Choosing Herbs of Bitter and Sour Flavors to Counteract Sweet Flavor. According to TCM theory, four-qi and fiveflavor theory are one of the basic concepts, and the method of "bitter and sour flavors to counteract sweet flavor" is a great approach to lower blood glucose levels. Bitter flavor is in direct opposition to sweet flavor, and sour flavor can neutralize sweet flavor [47]. Herbs with bitter and sour flavors are excellent when used to treat hyperglycemia. Herbs with a bitter flavor are based on San Huang Tang, Longdancao (Radix et Rhizoma Gentianae), Kushen (Radix Sophorae Flavescentis), Kuding (Herba Corydalis Bungeanae), and Shanzhizi (Fructus Gardeniae) and also could be considered, which generally include bitter flavor and cold property. Herbs of sour flavor are represented by Fructus Mume formula, Shanzhuyu (Fructus Corni), Suanzaoren (Semen
Ziziphi Spinosae), and Shiliupi (Pericarpium Granati) and should also be considered [48].

4.3. Choosing Formulas and Herbs Aimed at Main Symptoms. Alleviating the main symptoms is important in treating T2DM and its complications; thus, the selection of formulas and herbs should be based on the main symptoms. For example, vomiting is the most troublesome problem for diabetics with severe gastroparesis (DGP), Xiao-Banxia-Tang combined with Suye Huanglian Yin is commonly used to relieve nausea and vomiting [49-51]. Proteinuria and edema are obvious symptoms for $\mathrm{DN}$, which could be improved by Liuwei Dihuang Decoction $[52,53]$ and large amounts of Huangqi (Radix Astragali), Danshen (Salvia miltiorrhiza), and Fuling (Poria) [54, 55]. DPN patients with acral numbness and pain could be treated with Huangqi Guizhi Wu Wu Decoction [56] and large amounts of Chuanwu (Radix Aconiti Praeparata) [57] to improve symptoms and increase nerve conduction velocities (NCVs). The details showed in Table 3.

4.4. Applying Modern Pharmacological Achievements. With the development of modern pharmacological products, the effective components provide evidence for herbs or formulas to treat diseases [58]. There are several herbs that possess definite hypoglycemic effects and are often used in the traditional Chinese formulas for T2DM and its complications, including Huanglian (Rhizoma Coptidis), Huangqin (Radix Scutellariae), Renshen (Radix et Rhizoma Ginseng), Zhimu (Rhizoma Anemarrhenae), and Tianhuafen (Radix Trichosanthis) $[4,16]$. Details are shown in Table 2. Some herbs have great effects on improving other indicators, Weilingxian (Radix et Rhizoma Clematidis) may lower the blood uric acid [59], Wuweizi (Fructus Schisandrae Chinensis) may lower the aminotransferase [60], and Yinchen (Herba Artemisiae Scopariae) and Huzhang (Rhizoma Polygoni Cuspidati) may improve fatty liver $[61,62]$. In the clinical setting, the application of pharmacological products plays an important role in the treatment of DM.

\section{Importance of Drug Dose in the Treatment of Diabetes}

The therapeutic efficacy of TCM may be not only determined by syndrome differentiation, formula compatibility, medicinal properties and quality, water decoction, and administration method but also closely related to the applicable drug dose. As the saying goes, "the secret of traditional Chinese medicine is in the dose," the dose of herbs has always been difficult to study [63].

According to traditional concept, Chinese herbal medicines are only considered supplementary treatment for lowering the blood glucose. However, we have confirmed that Chinese herbal medicine possesses independent antihyperglycemic effects based on large scales of randomized controlled trials (RCTs), and adverse events were less common than with metformin [38]. The key point to lowering the blood glucose independently is dose. In our previous study, we demonstrated the relationship 
TABLE 1: Classical formulas and Chinese herbs recommended for T2DM treatment.

\begin{tabular}{|c|c|c|c|c|}
\hline Stage & Syndrome & Formula & Efficacy & Components \\
\hline \multirow[t]{2}{*}{ Stagnation } & $\begin{array}{l}\text { Qi stagnation due to } \\
\text { liver depression }\end{array}$ & Xiaoyao Powder & $\begin{array}{l}\text { Soothing the liver, } \\
\text { dissipating stagnation } \\
\text { of qi }\end{array}$ & $\begin{array}{l}\text { Radix Bupleuri, Radix Angelicae Sinensis, } \\
\text { Yam, Atractylodes, Poria cocos, } \\
\text { Glycyrrhiza, Herba Menthae, Rhizoma } \\
\text { Zingiberis Recens. }\end{array}$ \\
\hline & $\begin{array}{l}\text { Spleen and stomach } \\
\text { congestion }\end{array}$ & Houpo Sanwu Tang & $\begin{array}{l}\text { Moving qi, } \\
\text { removing food stagnation }\end{array}$ & $\begin{array}{l}\text { Officinal Magnolia Bark, Rhubarb, } \\
\text { Gardenia. }\end{array}$ \\
\hline \multirow{6}{*}{ Heat } & $\begin{array}{l}\text { Liver and stomach } \\
\text { stagnated heat }\end{array}$ & Da Chaihu Tang & $\begin{array}{l}\text { Clearing liver heat, } \\
\text { draining stomach fire }\end{array}$ & $\begin{array}{l}\text { Radix Bupleuri, Radix Scutellariae, } \\
\text { Rhubarb, Gardenia, Yam, Rhizoma } \\
\text { Pinelliae, Rhizoma Zingiberis Recens, } \\
\text { Fructus Jujubae. }\end{array}$ \\
\hline & $\begin{array}{l}\text { Lung and stomach } \\
\text { exuberant heat }\end{array}$ & Bai Hu Tang & $\begin{array}{l}\text { Clearing lung heat, } \\
\text { engendering fluids to } \\
\text { quench thirst }\end{array}$ & $\begin{array}{l}\text { Gypsum Fibrosum, Rhizoma } \\
\text { Anemarrhenae, Oryza sativa L., } \\
\text { Glycyrrhiza. }\end{array}$ \\
\hline & $\begin{array}{l}\text { Stomach and intestine } \\
\text { excessive heat }\end{array}$ & $\begin{array}{l}\text { Dahuang Huanglian } \\
\text { Xie Xin Tang }\end{array}$ & $\begin{array}{l}\text { Draining stomach and } \\
\text { intestine fire }\end{array}$ & $\begin{array}{l}\text { Rhubarb, Rhizoma Coptidis, Radix } \\
\text { Scutellariae. }\end{array}$ \\
\hline & $\begin{array}{l}\text { Intestinal damp and } \\
\text { heat }\end{array}$ & Gegen Qin Lian Tang & $\begin{array}{l}\text { Clearing heat and draining } \\
\text { dampness }\end{array}$ & $\begin{array}{l}\text { Pueraria, Rhizoma Coptidis, Radix } \\
\text { Scutellariae, Glycyrrhiza. }\end{array}$ \\
\hline & $\begin{array}{l}\text { Phlegm and heat } \\
\text { stasis }\end{array}$ & Xiao Xian Xiong Tang & $\begin{array}{l}\text { Clearing heat and } \\
\text { dissolving phlegm }\end{array}$ & $\begin{array}{l}\text { Rhizoma Coptidis, Rhizoma Pinelliae, } \\
\text { Semen Trichosanthis. }\end{array}$ \\
\hline & Intense heat toxin & $\begin{array}{l}\text { San Huang Tang plus } \\
\text { Wu Wei Xiao Du Yin }\end{array}$ & $\begin{array}{l}\text { Draining fire and resolving } \\
\text { toxins }\end{array}$ & $\begin{array}{l}\text { Rhizoma Coptidis, Radix Scutellariae, } \\
\text { Rhubarb, Flos Lonicerae Japonicae, Flos } \\
\text { Chrysanthemi Indici, Herba Taraxaci, } \\
\text { Herba Violae, Herba Begoniae } \\
\text { Fimbristipulatae. }\end{array}$ \\
\hline \multirow{5}{*}{ Deficiency } & $\begin{array}{l}\text { Deficiency of body } \\
\text { liquid due to excessive } \\
\text { heat }\end{array}$ & $\begin{array}{l}\text { Bai Hu plus Renshen } \\
\text { Tang }\end{array}$ & $\begin{array}{l}\text { Clearing lung heat, } \\
\text { promoting fluid production }\end{array}$ & $\begin{array}{l}\text { Gypsum Fibrosum, Rhizoma } \\
\text { Anemarrhenae, Oryza Sativa L., } \\
\text { Glycyrrhiza, Ginseng. }\end{array}$ \\
\hline & $\begin{array}{l}\text { Effulgent fire due to } \\
\text { yin deficiency }\end{array}$ & Zhi Bai Dihuang Wan & $\begin{array}{l}\text { Enriching yin, } \\
\text { clearing the fire }\end{array}$ & $\begin{array}{l}\text { Rhizoma Anemarrhenae, Cortex } \\
\text { Phellodendri, Radix Rehmanniae, Radix } \\
\text { Asparragi Officinalis, Rhizoma } \\
\text { Dioscoreae, Poria cocos, Rhizoma } \\
\text { Alismatis, Cortex moutan. }\end{array}$ \\
\hline & $\begin{array}{l}\text { Dual deficiency of qi } \\
\text { and yin }\end{array}$ & $\begin{array}{l}\text { Sheng Mai Yin plus } \\
\text { Zeng Ye Tang }\end{array}$ & $\begin{array}{l}\text { Boosting qi and nourishing } \\
\text { yin }\end{array}$ & $\begin{array}{l}\text { Ginseng, Radix Ophiopogonis, Fructus } \\
\text { Schisandrae Chinensis, Radix } \\
\text { scrophulariae, Radix Rehmanniae. }\end{array}$ \\
\hline & $\begin{array}{l}\text { Spleen deficiency and } \\
\text { stomach congestion }\end{array}$ & Banxia Xie Xin Tang & $\begin{array}{l}\text { Dispersing stagnation with } \\
\text { bitter-acrid medicinals }\end{array}$ & $\begin{array}{l}\text { Rhizoma Pinelliae, Zingiberis, Ginseng, } \\
\text { Rhizoma Coptidis, Radix Scutellariae, } \\
\text { Fructus Jujubae, Glycyrrhiza. }\end{array}$ \\
\hline & $\begin{array}{l}\text { Cold and heat in } \\
\text { complexity }\end{array}$ & Wumei Wan & $\begin{array}{l}\text { Clearing the upper and } \\
\text { warming the lower }\end{array}$ & $\begin{array}{l}\text { Fructus Mume, Herba Asari, Zingiberis, } \\
\text { Rhizoma Coptidis, Radix Angelicae } \\
\text { Sinensis, Typhonii Gigantei, Fructus } \\
\text { Zanthoxyli, Ramulus Cinnamomi, } \\
\text { Ginseng, Cortex Phellodendri. }\end{array}$ \\
\hline \multirow{3}{*}{ Damage } & $\begin{array}{l}\text { Liver-kidney yin } \\
\text { deficiency }\end{array}$ & Qi Ju Dihuang Wan & $\begin{array}{l}\text { Enriching and nourishing } \\
\text { the liver and kidney }\end{array}$ & $\begin{array}{l}\text { Fructus Lycii, Flos Chrysanthemi, Radix } \\
\text { Rehmanniae, Radix Asparragi Officinalis, } \\
\text { Rhizoma Dioscoreae, Poria cocos, } \\
\text { Rhizoma Alismatis, Cortex moutan. }\end{array}$ \\
\hline & $\begin{array}{l}\text { Dual deficiency of yin } \\
\text { and yang }\end{array}$ & Jin Gui Shen Qi Wan & $\begin{array}{l}\text { Enriching yin and } \\
\text { supplementing yang }\end{array}$ & $\begin{array}{l}\text { Typhonii Gigantei, Cortex Cinnamomi, } \\
\text { Radix Rehmanniae, Radix Asparragi } \\
\text { Officinalis, Rhizoma Dioscoreae, Poria } \\
\text { cocos, Alisma, Cortex moutan. }\end{array}$ \\
\hline & $\begin{array}{l}\text { Spleen-kidney yang } \\
\text { deficiency }\end{array}$ & Fuzi Li Zhong Wan & $\begin{array}{l}\text { Warming and } \\
\text { supplementing the spleen } \\
\text { and kidney }\end{array}$ & $\begin{array}{l}\text { Typhonii Gigantei, Zingiberis, Ginseng, } \\
\text { Atractylodes, Glycyrrhiza. }\end{array}$ \\
\hline
\end{tabular}


TABLE 2: Classifications of function of herbal medicines possessing hypoglycemic efficacy.

\begin{tabular}{|c|c|}
\hline TCM efficacies & Herbal medicines \\
\hline Clearing heat & $\begin{array}{l}\text { Huanglian (Rhizoma Coptidis), Tianhuafen (Radix trichosanthis), Zhimu (Rhizoma } \\
\text { Anemarrhenae), Huangbai (Cortex Phellodendri), Gegen (Radix Puerariae), Kugua } \\
\text { (Fructus Balsampear), Shigao (Gypsum Fibrosum), Huangqin (Radix Scutellariae), Zhizi } \\
\text { (Fructus Coini), Digupi (Cortex Lycii Radicis), Lugen (Rhizoma Phragmitis) }\end{array}$ \\
\hline $\begin{array}{l}\text { Nourishing yin (promoting body fluids } \\
\text { production) }\end{array}$ & $\begin{array}{l}\text { Dihuang (Radix Rehmanniae), Shanzhuyu (Radix Asparragi Officinalis), Wumei (Fructus } \\
\text { Mume), Yuzhu (Rhizoma Polygonati Odorati), Maidong (Radix Ophiopogonis), Gouqizi } \\
\text { (Fructus Lycii), Nvzhenzi (Fructus Ligustri Lucidi), Wuweizi (Fructus Schisandrae), Shihu } \\
\text { (Herba Dendrobii), Shengmuli (Concha Ostreae), Xuanshen (Radix Scrophulariae) }\end{array}$ \\
\hline Invigorating qi (fortifying the spleen) & $\begin{array}{l}\text { Huangqi (Radix Astragali seu Hedysari), Renshen (Radix Ginseng), Huangjing (Rhizoma } \\
\text { polygonati), Cangzhu (Rhizoma Atractylodis), Shanyao (Rhizoma Dioscoreae), Yiyiren } \\
\text { (Semen Coicis) }\end{array}$ \\
\hline Activating stasis & $\begin{array}{l}\text { Danshen (Radix Salviae Miltiorrhizae), Sanqi (Radix Notoginseng), Guijianyu (Ramulus } \\
\text { Euonymi), Chishao (Radix Paeoniae Rubra), Shuizhi (Hirudo), Chuanxiong (Rhizoma } \\
\text { Ligustici Chuanxiong), Danggui (Radix Angelicae Sinensis), Taoren (Semen Persicae) }\end{array}$ \\
\hline Warming yang & $\begin{array}{l}\text { Tusizi (Semen Cuscutae), Yinyanghuo (Herba Epimedii), Dongchongxiacao (Cordyceps), } \\
\text { Bajitian (Radix Morindae oficinalis), Roucongrong (Herba Cistanches), Dasuan (Allii } \\
\text { Sativi Bulbus), Buguzhi (Fructus Psoraleae), Fuzi (Radix Aconiti Lateralis Praeparata) }\end{array}$ \\
\hline Draining water & $\begin{array}{l}\text { Zexie (Rhizoma Alismatis), Fuling (Poria cocos), Yumixu (Stigma Maydis), Dongguapi } \\
\text { (Exocarpium Benincasae) }\end{array}$ \\
\hline
\end{tabular}

TABLE 3: Chinese herbal formulas mentioned in the review.

\begin{tabular}{ll}
\hline Formulas & Components \\
\hline & $\begin{array}{l}\text { Shanyao (Rhizoma Dioscoreae), Huangqi } \\
\text { (Radix Astragali seu Hedysari), Zhimu } \\
\text { (Rhizoma Anemarrhenae), Jineijin } \\
\text { Yuye Tang }\end{array}$ \\
& $\begin{array}{l}\text { Gegen (Radix Puerariae), Wumei } \\
\text { (Fructus Mume), Tianhuafen (Radix } \\
\text { Trichosanthis) }\end{array}$ \\
\hline Xiao Banxia Tang & $\begin{array}{l}\text { Banxia (Rhizoma Pinelliae), Shengjiang } \\
\text { (Rhizoma Zingiberis Recens) }\end{array}$ \\
\hline Suye Huanglian Yin & $\begin{array}{l}\text { Huanglian (Rhizoma Coptidis), Zisuye } \\
\text { (Folium Perillae) }\end{array}$ \\
\hline Huangqi Guizhi Wu & $\begin{array}{l}\text { Huang Qi (Radix Astragali seu Hedysari), } \\
\text { Gui Zhi (Ramulus Cinnamomi), Shanyao } \\
\text { (Rhizoma Dioscoreae), Sheng Jiang } \\
\text { (Rhizoma Zingiberis Recens), Da Zao } \\
\text { (Fructus Jujubae) }\end{array}$ \\
\hline Dang & $\begin{array}{l}\text { Dahuang (Rhubarb), Shuizhi (Hirudo), } \\
\text { Taoren (Semen Persicae), Mangchong } \\
\text { (Tabanus) }\end{array}$ \\
\hline
\end{tabular}

between dose and effect through RCTs. One hundred and eighty-seven T2DM patients were randomly allocated to receive high $(\mathrm{HD}, n=44)$, moderate $(\mathrm{MD}, n=52)$, and low doses (LD, $n=50$ ) of Gegen Qin Lian Decoction or the placebo $(n=41)$ for 12 weeks. Patients that received the $\mathrm{HD}$ or MD showed significant difference in adjusted mean changes from baseline of HbAlc and FBG compared with the LD and placebo groups. The dose-effect relationship is obvious [64]. Huanglian is commonly used in the heat and deficiency stages of T2DM [22]. Liu made a survey of the dose of Huanglian in 1,321 effective formulas (when the decreased percentage of FBG and PBG was $>20 \%$ of those before treatment or the decreased percentage of HbAlc was $>10 \%$ of that before treatment within 12 weeks, the formula was thought of as an effective formula, and other else was thought of as an ineffective formula) to treat T2DM, and the result showed that commonly recommended dose of Huanglianwas $15 \mathrm{~g}$ when FBG $<7 \mathrm{mmol} / \mathrm{L}, 30 \mathrm{~g}$ when $\mathrm{FBG}<$ $10 \mathrm{mmol} / \mathrm{L}$, and $30 \mathrm{~g}$ to $45 \mathrm{~g}$ when $\mathrm{FBG}$ was $\geq 10 \mathrm{mmol} / \mathrm{L} \mathrm{[48]}$. There is a positive correlation between the dose of Huanglian and the decrease of blood glucose.

Chuanwu (Radix Aconiti Praeparata) is commonly used in the treatment of DPN with severe acral pain, tingling, and cold. The recommended dose of Chuanwu (Radix Aconiti Praeparata) should be "15-60 g," even to a maximum dose of $120 \mathrm{~g}$ for alleviating the pain, whereas the routine dose of "1.5-3 g" in Chinese Pharmacopoeia (2010 edition) is usually ineffective. The decocted time of Chuanwu (Radix Aconiti Praeparata) should be more than 60 mins, and medicinal compatibility with Gancao (Radix et Rhizoma Glycyrrhizae) or Baimi $(\mathrm{Mel})$ is also necessary to resolve toxins [57]. Banxia (Rhizoma Pinelliae) and Shengjiang (Rhizoma Zingiberis Recens) are often used for treating DGP nausea and vomiting. The routine doses of Banxia (Rhizoma Pinelliae) and Shengjiang (Rhizoma Zingiberis Recens) are "3-9 g" and "3$9 \mathrm{~g}$," respectively, whereas the recommended dose of Banxia (Rhizoma Pinelliae) should be "15-60 g," and the dose of Shengjiang (Rhizoma Zingiberis Recens) should be "15-30 g" $[50,65,66]$.

\section{Discussion}

With the increasing incidence of obesity, T2DM is likely to become even more prevalent in the future. It has a significant impact on the quality of life and the number 
of deaths as well as on the financial resources of the public health care system. Currently, CAM therapies are widespread in both developing and developed countries. Due to positive views of patients regarding CAM therapies and the increased availability of them, they are frequently used for T2DM globally [67]. The commonly used CAM therapies include Chinese herbal medicines, acupuncture, nutritional supplements and advice, spiritual healing, and relaxation techniques [7]. Recently, treating obese T2DM with acupuncture has become popular, and a lot of progress has been made to indicate that acupuncture is safe and effective [68]. Chinese herbal medicine contains various active ingredients, which could provide multiple therapeutic effects on multiple targets, such as enhancement of insulin sensitivity, stimulation of insulin secretion, or reduction of carbohydrate absorption [16]. Chinese herbal medicines could also help treat the diabetic complications by ameliorating abnormalities related to blood viscosity, microcirculation, and oxidative stress [69]. In the light of recent studies, it is not difficult to find that the etiology, pathogenesis, and therapeutic strategies of diabetes have been changed recently. With the development of modern diagnosis and treatment on DM, the thoughts of highlighting the combination of symptoms, syndromes, and diseases, reunderstanding the etiology and pathogenesis of diabetes, emphasizing heatclearing and invigorating blood circulation, and choosing formula and herbs are based on the combination of TCM theory and current medicine, and paying attention to dosage has been gradually and widely accepted; only by adopting these thoughts, the clinical efficacy of Chinese formulas and herbs on DM may be improved. We have confirmed the effects of formulas and herbs on regulating metabolic problems from integrated perspectives. For example, obese diabetes patients have hyperglycemia along with fatty liver, hyperlipidemia, hypertension, hyperuricemia, and other metabolic disorders. Western medicine has not found an effective way to treat the metabolic syndrome; each abnormality has been treated separately. Here, we take advantage of TCM with a holistic approach. Furthermore, formulas and herbs may also reverse risk factors leading to diabetes. In one study, we observed that the Chinese herbal formula Tianqi Jiang Tang Capsule reduced progression from impaired glucose tolerance (IGT) to diabetes. After a 12-month treatment, results demonstrated that Tianqi significantly decreased the incidence of T2DM in subjects with IGT by $32.1 \%$ compared with placebo [70]. There are also diverse Chinese patent drugs commonly used for treating DM clinically, including Xiaoke Wan, Jiangtangjia Pian, YuquanWan, and Tangmaikang Keli, which also play an important role [4]. In the clinical setting, a large amount of clinical experience has been accumulated, and these innovative thoughts have been gradually accepted and promoted the development of TCM. The emergence of evidence-based medicine (EBM) has provided objective efficacy assessment of TCM with new thoughts and methods [71]; well-designed, large-scale, high-quality multicenter RCTs are still required to provide stronger evidence in the future. With continuous efforts, TCM will undoubtedly play a more important role in fighting T2DM.

\author{
Abbreviations \\ DM: Diabetes mellitus \\ T2DM: Type 2 diabetes mellitus \\ TCM: Traditional Chinese medicine \\ BBR: Berberine \\ HbAlC: Hemoglobin Alc \\ FBG: $\quad$ Fasting blood glucose \\ PBG: Postprandial blood glucose \\ CHO: Cholesterol \\ TG: $\quad$ Triglyceride \\ HDL-C: High-density lipoprotein \\ LDL-C: Low-density lipoprotein \\ BMI: $\quad$ Body mass index \\ Cr: Creatinine \\ BUN: Blood urea nitrogen \\ RCTs: Randomized controlled trials.
}

\section{Conflict of Interests}

No competing financial interests existed.

\section{Authors' Contribution}

Xiao-Lin Tong and Lin-Hua Zhao proposed the paper topic; the two of them contributed equally to this work and are both co-corresponding authors; Bing Pang and Qiang Zhou wrote the paper; the two of them contributed equally to this work and are both co-first authors; Tian-Yu Zhao consulted the references; Li-Sha He and Hong-Dong Chen drew the figures; Jing Guo and Lin-Hua Zhao revised the paper.

\section{Acknowledgments}

This study is supported by a grant from the National Basic Research Program of China (“973” Program, no. 2010CB530601) and the Major Program of the National Natural Science Foundation of China (Grant no. 81430097). The authors thank LetPub (http://www.letpub.com/) for its linguistic assistance during the preparation of this paper.

\section{References}

[1] International Diabetes Federation, IDF Diabetes Altas Globally, International Diabetes Federation, 6th edition, 2013, http://www.idf.org/diabetesatlas.

[2] W. Y. Yang, J. M. Lu, J. P. Weng et al., "Prevalence of diabetes among men and women in China," The New England Journal of Medicine, vol. 362, no. 12, pp. 1090-1101, 2010.

[3] Z. Wang, J. Wang, and P. Chan, "Treating type 2 diabetes mellitus with traditional chinese and indian medicinal herbs," Evidence-Based Complementary and Alternative Medicine, vol. 2013, Article ID 343594, 17 pages, 2013.

[4] W. Xie, Y. Zhao, and Y. Zhang, "Traditional Chinese medicines in treatment of patients with type 2 diabetes mellitus," EvidenceBased Complementary and Alternative Medicine, vol. 2011, Article ID 726723, 13 pages, 2011.

[5] P. Zimmet, K. G. M. M. Alberti, and J. Shaw, "Global and societal implications of the diabetes epidemic," Nature, vol. 414, no. 6865, pp. 782-787, 2001. 
[6] S. El-Kaissi and S. Sherbeeni, "Pharmacological management of type 2 diabetes mellitus: an update," Current Diabetes Reviews, vol. 7, no. 6, pp. 392-405, 2011.

[7] G. Ning, J. Hong, Y. Bi et al., "Progress in diabetes research in China," Zhong Guo Tang Niao Bing Za Zhi, vol. 1, no. 3, pp. 163$172,2009$.

[8] X. L. Tong, L. Dong, L. Chen, and Z. Zhen, “Treatment of diabetes using traditional Chinese medicine: past, present and future," The American Journal of Chinese Medicine, vol. 40, no. 5, pp. 877-886, 2012.

[9] L. P. Zhu, X. Li, and Z. P. Xu, "The diagnostic and therapeutic system of 'combination of symptom, syndrome and disease' in the clinic," Liao Ning Zhong Yi Za Zhi, vol. 37, no. 10, pp. 19381939, 2010.

[10] X. L. Tong, "The clinical application on the thought of combination of symptom, syndrome and disease," Zhong Yi Za Zhi, vol. 51, no. 4, pp. 300-303, 2010.

[11] C. Keji and X. Hao, "The integration of traditional Chinese medicine and Western medicine," European Review, vol. 11, no. 2, pp. 225-235, 2003.

[12] F. Cheung, “TCM: made in China," Nature, vol. 480, no. 7378, pp. S82-S83, 2011.

[13] K. J. Chen, “Clinical service of Chinese medicine," Zhong Guo Zhong Xi Yi Jie He Za Zhi, vol. 14, no. 3, pp. 163-164, 2008.

[14] Y. Q. Ou, Diagnostics in the Clinic, People's Medical Publishing House, 2005.

[15] Q. Wang, "The present situation of TCM treatment for diabetes and its researches," Journal of Traditional Chinese Medicine, vol. 23, no. 1, pp. 67-73, 2003.

[16] W. L. Li, H. C. Zheng, J. Bukuru, and N. de Kimpe, "Natural medicines used in the traditional Chinese medical system for therapy of diabetes mellitus," Journal of Ethnopharmacology, vol. 92, no. 1, pp. 1-21, 2004.

[17] Y. Liu, L. Lin, Q. Ni, and M. D. Li, "Curative effect evaluation of ziyi granules for deficiency of both Qi and Yin in type 2 diabetes mellitus patients," Yi Xue Yan Jiu Za Zhi, vol. 41, no. 1, pp. 42-44, 2012.

[18] X. M. Liu, L. Chen, L. Dong et al., "Discussion of formulation and pathogenesis of T2DM," Shi Jie Zhong Xi Yi Jie He Za Zhi, vol. 2, no. 12, pp. 686-689, 2007.

[19] N. G. Clark, K. M. Fox, and S. Grandy, "Symptoms of diabetes and their association with the risk and presence of diabetes: findings from the study to help improve early evaluation and management of risk factors leading to diabetes (SHIELD)," Diabetes Care, vol. 30, no. 11, pp. 2868-2873, 2007.

[20] J. Y. Su and W. Y. Yang, “The hyperglycemic process began with monitoring," Yao Pin Ping Jia, vol. 6, no. 1, pp. 15-16, 2009.

[21] C. Daousi, I. F. Casson, G. V. Gill, I. A. MacFarlane, J. P. H. Wilding, and J. H. Pinkney, "Prevalence of obesity in type 2 diabetes in secondary care: association with cardiovascular risk factors," Postgraduate Medical Journal, vol. 82, no. 966, pp. 280284, 2006.

[22] X. L. Tong, W. K. Liu, J. Wang, Q. Ni, and J. P. Wei, "Key points of syndrome differentiation and practical application of stagnation, heat, deficiency and damage, four stages of diabetes," Ji Lin Zhong Yi Yao Za Zhi, vol. 32, no. 6, pp. 442-444, 2012.

[23] W. D. Li, Y. S. Wang, X. H. Su et al., "Clinical observation on Qingre Quzhuo Capsule for 52 cases of diabetes combined with metabolic syndrome," Zhong Xi Yi Jie He Xin Nao Xue Guan Bing Za Zhi, vol. 9, no. 7, pp. 797-798, 2011.
[24] Q. Yi, X.-E. He, K.-F. Luo et al., "Protection of long-term treatment with huang-lian-jie-du-tang on vascular endothelium in rats with type 2 diabetes mellitus," Current Therapeutic Research-Clinical and Experimental, vol. 73, no. 6, pp. 174-185, 2012.

[25] V. Poitout and R. P. Robertson, "Glucolipotoxicity: fuel excess and $\beta$-cell dysfunction," Endocrine Reviews, vol. 29, no. 3, pp. 351-366, 2008.

[26] J. Y. Zhou, S. W. Zhou, K. B. Zhang et al., "Chronic effects of berberine on blood, liver glucolipid metabolism and liver PPARs expression in diabetic hyperlipidemic rats," Biological and Pharmaceutical Bulletin, vol. 31, no. 6, pp. 1169-1176, 2008.

[27] J. Yin, H. Xing, and J. Ye, "Efficacy of berberine in patients with type 2 diabetes mellitus," Metabolism: Clinical and Experimental, vol. 57, no. 5, pp. 712-717, 2008.

[28] C. S. Yang, G. Chen, and Q. Wu, "Recent scientific studies of a traditional Chinese medicine, tea, on prevention of chronic diseases," Journal of Traditional and Complementary Medicine, vol. 4, no. 1, pp. 17-23, 2014.

[29] A. Basu, K. Sanchez, M. J. Leyva et al., “Green tea supplementation affects body weight, lipids, and lipid peroxidation in obese subjects with metabolic syndrome," Journal of the American College of Nutrition, vol. 29, no. 1, pp. 31-40, 2010.

[30] C.-Y. Liu, C.-J. Huang, L.-H. Huang, I.-J. Chen, J.-P. Chiu, and C.-H. Hsu, "Effects of green tea extract on insulin resistance and glucagon-like peptide 1 in patients with type 2 diabetes and lipid abnormalities: a randomized, double-blinded, and placebo-controlled trial," PLoS ONE, vol. 9, no. 3, Article ID e91163, 2014.

[31] A. Dregan, J. Charlton, P. Chowienczyk, and M. C. Gulliford, "Chronic inflammatory disorders and risk of type 2 diabetes mellitus, coronary heart disease, and stroke: a population-based cohort study," Circulation, vol. 130, no. 10, pp. 837-844, 2014.

[32] W. Xie and L. Du, "Diabetes is an inflammatory disease: evidence from traditional Chinese medicines," Diabetes, Obesity and Metabolism, vol. 13, no. 4, pp. 289-301, 2011.

[33] Q. Yi, X.-E. He, K.-F. Luo et al., "Protection of long-term treatment with Huang-Lian-Jie-Du-Tang on vascular endothelium in rats with type 2 diabetes mellitus," Current Therapeutic Research-Clinical and Experimental, vol. 73, no. 6, pp. 174-185, 2012.

[34] J. Lu, J.-S. Wang, and L.-Y. Kong, "Anti-inflammatory effects of Huang-Lian-Jie-Du decoction, its two fractions and four typical compounds," Journal of Ethnopharmacology, vol. 134, no. 3, pp. 911-918, 2011.

[35] H. Zeng, X. Liu, S. Dou et al., "Huang-Lian-Jie-Du-Tang exerts anti-inflammatory effects in rats through inhibition of nitric oxide production and eicosanoid biosynthesis via the lipoxygenase pathway," Journal of Pharmacy and Pharmacology, vol. 61, no. 12, pp. 1699-1707, 2009.

[36] L. J. Wang and Q. Xu, "Mechanism of anti-inflammatory action of Huanglian Jiedu decoction a traditional Chinese prescription," Zhongguo Zhong Yao Za Zhi, vol. 25, no. 8, pp. 493-496, 2000.

[37] H.-J. Wang and B.-H. Chiang, "Anti-diabetic effect of a traditional Chinese medicine formula," Food \& Function, vol. 3, no. 11, pp. 1161-1169, 2012.

[38] F. M. Lian, Z. X. Wei, X. F. Lv et al., "Clinical RCT study on the effect of Kaiyu Qingre Jiangzhuo prescription on type 2 diabetes," Shi Jie Zhong Xi Yi Jie He Za Zhi, vol. 3, no. 1, pp. 32-35, 2008. 
[39] H. Taniwaki, T. Shoji, M. Emoto et al., "Femoral artery wall thickness and stiffness in evaluation of peripheral vascular disease in type 2 diabetes mellitus," Atherosclerosis, vol. 158, no. 1, pp. 207-214, 2001.

[40] Z.-H. Fang, Y. Liu, T.-T. Bao et al., "Effect of Danzhijiangtang capsule on monocyte chemoattractant protein-1 mRNA expression in newly diagnosed diabetes subclinical vascular lesions," World Journal of Gastroenterology, vol. 19, no. 19, pp. 2963-2968, 2013.

[41] Y. L. Wu, Study of Collateral Diseases, China Press of Traditional Chinese Medicine, 2005.

[42] X. L. Tong, “TCM theoretical application on 'treat disease before it arises' and 'unblock the collateral vessels' in the treatment of diabetes and its complications," Zhong Yi Za Zhi, vol. 48, no. 6, pp. 484-486, 2007.

[43] Y. Y. Song and J. Yang, "Treatment of diabetic vascular complications using the theory of collateral diseases," Nang Jing Zhong Yi Yao Da Xue Xue Bao, vol. 30, no. 5, pp. 406-409, 2014.

[44] X. W. Yang, F. Q. Liu, J. J. Guo et al., "Antioxidation and antiinflammatory activity of Tang Bi Kang in rats with diabetic peripheral neuropathy," BMC Complementary and Alternative Medicine, vol. 15, no. 1, article 66, 2015.

[45] N. Zhang, Y. Gao, D. Zou et al., "Effects of Chinese medicine Tong xinluo on diabetic nephropathy via inhibiting TGF- $\beta 1-$ induced epithelial-to-mesenchymal transition," Evidence-Based Complementary and Alternative Medicine, vol. 2014, Article ID 123497, 17 pages, 2014.

[46] D. Gao, Y. Guo, X. Li et al., "An aqueous extract of Radix Astragali, Angelica sinensis, and Panax notoginseng is effective in preventing diabetic retinopathy," Evidence-Based Complementary and Alternative Medicine, vol. 2013, Article ID 578165, 11 pages, 2013.

[47] Z. M. Li, X. D. Liu, and L. Qiao, "Application of 'Ku Suan Zhi Tian' method in the treatment of Xiao Ke," Guo Yi Lun Tan, vol. 29, no. 3, pp. 59-60, 2014.

[48] W. K. Liu, The Analysis of Regularity of Treating Diabetes with 'Ku Suan Zhi Tian' Method on the Basis of Clinic Data Mining, China Academy of Chinese Medical Sciences, 2010.

[49] Q. Qian, W. Chen, W. Yue, Z. Yang, Z. Liu, and W. Qian, "Antiemetic effect of Xiao-Ban-Xia-Tang, a Chinese medicinal herb recipe, on cisplatin-induced acute and delayed emesis in minks," Journal of Ethnopharmacology, vol. 128, no. 3, pp. 590593, 2010.

[50] B. Pang, Q. Zhou, J. L. Li et al., "Treatment of refractory diabetic gastroparesis: western medicine and traditional Chinese medicine therapies," World Journal of Gastroenterology, vol. 20, no. 21, pp. 6504-6514, 2014.

[51] C. Y. Zhang, "Eighty cases of vomiting of pregnancy treated by modified Su Ye Huang Lian Tang," He Nan Zhong Yi Xue Yuan Xue Bao, vol. 19, no. 4, p. 60, 2004.

[52] H. He, X. Yang, X. Zeng et al., "Protective effect of Liuwei Dihuang decoction on early diabetic nephropathy induced by streptozotocin via modulating ET-ROS axis and matrix metalloproteinase activity in rats," Journal of Pharmacy and Pharmacology, vol. 59, no. 9, pp. 1297-1305, 2007.

[53] J. L. Chen and F. M. Ling, "The influence of Liu Wei Di Huang Wan on albuminuria in early stage of diabetic nephropathy," Xin Zhong Yi, vol. 36, no. 12, pp. 26-27, 2004.

[54] Z.-M. Lu, Y.-R. Yu, H. Tang, and X.-X. Zhang, "The protective effects of Radix Astragali and Rhizoma Ligustici Chuanxiong on endothelial dysfunction in type 2 diabetic patients with microalbuminuria," Sichuan Da Xue Xue Bao Yi Xue Ban, vol. 36, no. 4, pp. 529-532, 2005.

[55] T. Z. Wang, Y. Chen, Y. M. He et al., "Effects of Chinese herbal medicine Yiqi Huaju Qingli Formula in metabolic syndrome patients with microalbuminuria: a randomized placebocontrolled trial," Chinese Journal of Integrative Medicine, vol. 11, no. 3, pp. 175-183, 2013.

[56] Y. Tong and H. Hou, "Effects of Huangqi Guizhi Wuwu Tang on diabetic peripheral neuropathy," Journal of Alternative and Complementary Medicine, vol. 12, no. 6, pp. 506-509, 2006.

[57] L. Feng, W.-K. Liu, L. Deng, J.-X. Tian, and X.-L. Tong, “Clinical efficacy of aconitum-containing traditional Chinese medicine for diabetic peripheral neuropathic pain," The American Journal of Chinese Medicine, vol. 42, no. 1, pp. 109-117, 2014.

[58] U. F. Ezuruike and J. M. Prieto, "The use of plants in the traditional management of diabetes in Nigeria: pharmacological and toxicological considerations," Journal of Ethnopharmacology, vol. 155, no. 2, pp. 857-924, 2014.

[59] Q. Fu, K. Zan, M. Zhao et al., "Triterpene saponins from clematis chinensis and their potential anti-inflammatory activity," Journal of Natural Products, vol. 73, no. 7, pp. 1234-1239, 2010.

[60] H. Kang and S. Koppula, “Olea europaea Linn. Fruit Pulp extract protects against carbon tetrachloride-induced hepatic damage in mice," Indian Journal of Pharmaceutical Sciences, vol. 76, no. 4, pp. 274-280, 2014.

[61] S. H. Hong, S. H. Seo, J. H. Lee, and B. T. Choi, "The aqueous extract from Artemisia capillaris Thunb. inhibits lipopolysaccharide-induced inflammatory response through preventing NF-kappaB activation in human hepatoma cell line and rat liver," International Journal of Molecular Medicine, vol. 13, no. 5, pp. 717-720, 2004.

[62] H. Zhang, C.-H. Yu, Y.-P. Jiang et al., "Protective effects of polydatin from Polygonum cuspidatum against carbon tetrachloride-induced liver injury in mice," PLOS ONE, vol. 7, no. 9, Article ID e46574, 2012.

[63] X. L. Tong, Y. S. Wang, Y. L. Fu et al., "Discussion on dose-effect relationship of medicinals and formulas," Zhong Yi Za Zhi, vol. 51, no. 11, pp. 965-967, 2010.

[64] J. Xu, F. M. Lian, L. H. Zhao et al., "Structural modulation of gut microbiota during alleviation of type 2 diabetes with a Chinese herbal formula," International Society for Microbial Ecology Journal, vol. 9, no. 3, pp. 552-562, 2015.

[65] Chinese Pharmacopoeia Commission, Pharmacopoeia of the People's Republic of China, China Medical Science Press, 2010.

[66] J. Li, M. Li, B. Pang et al., "Combination of symptoms, syndrome and disease: treatment of refractory diabetic gastroparesis," World Journal of Gastroenterology, vol. 20, no. 26, pp. 86748680, 2014.

[67] C. Vincent and A. Furnham, "Why do patients turn to complementary medicine? An empirical study," The British Journal of Clinical Psychology, vol. 35, no. 1, pp. 37-48, 1996.

[68] L. J. N. Ji and G. Z. Yin, “The general situation of treating obese type 2 diabetes mellitus with acupuncture," Xin Jiang Zhong Yi Yao Za Zhi, vol. 32, no. 1, pp. 72-75, 2014.

[69] T.-F. Tzeng, S.-S. Liou, and I.-M. Liu, “The selected traditional chinese medicinal formulas for treating diabetic nephropathy: perspective of modern science," Journal of Traditional and Complementary Medicine, vol. 3, no. 3, pp. 152-158, 2013.

[70] F. M. Lian, G. Li, X. Chen et al., "Chinese herbal medicine tianqi reduces progression from impaired glucose tolerance to 
diabetes: a double-blind, randomized, placebo-controlled, multicenter trial," Journal of Clinical Endocrinology \& Metabolism, vol. 99, no. 2, pp. 648-655, 2014.

[71] H. Xu and K.-J. Chen, "Making evidence-based decisions in the clinical practice of integrative medicine," Zhong Guo Zhong Xi Yi Jie He Za Zhi, vol. 16, no. 6, pp. 483-485, 2010. 


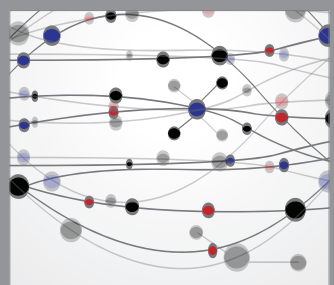

The Scientific World Journal
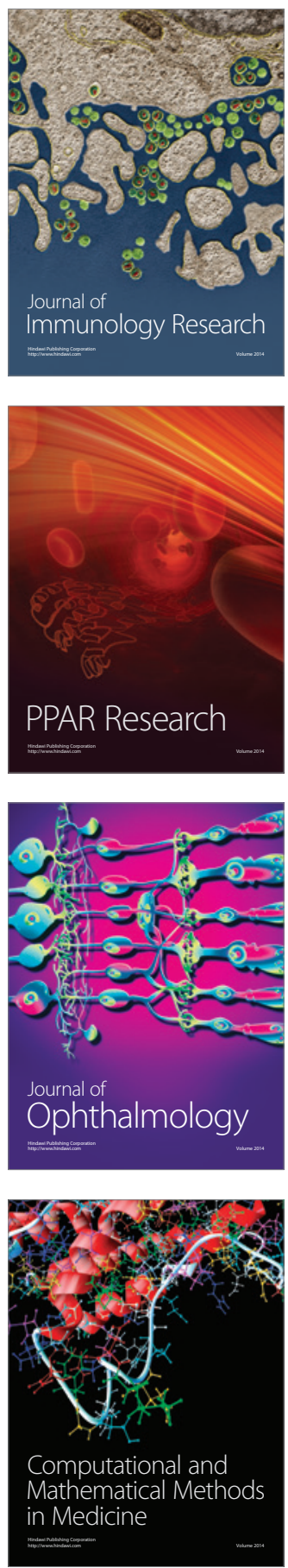

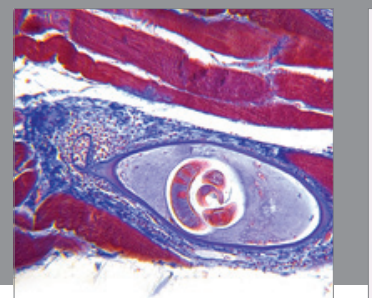

Gastroenterology

Research and Practice
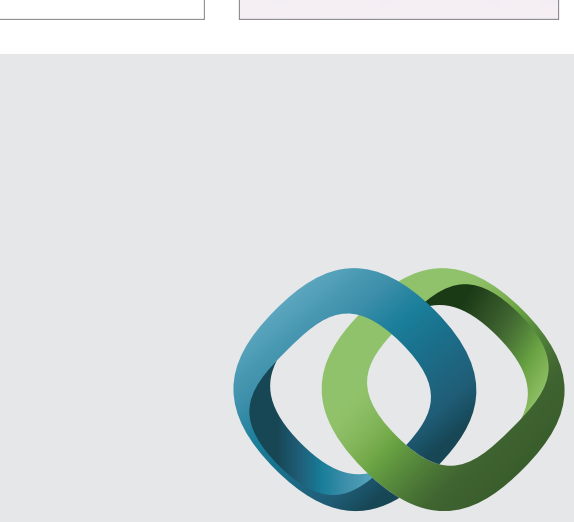

\section{Hindawi}

Submit your manuscripts at

http://www.hindawi.com
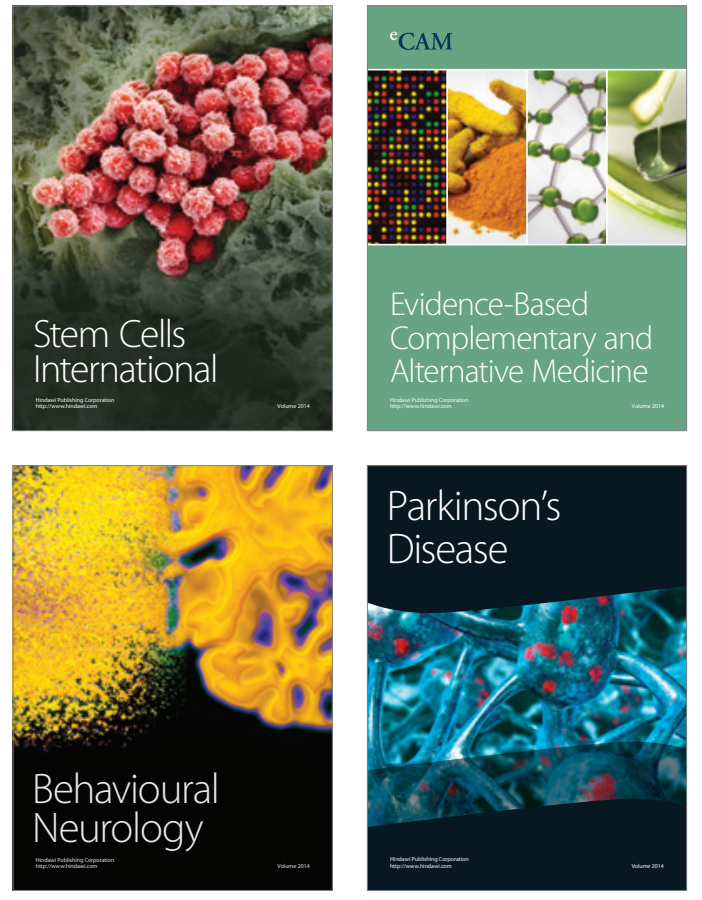
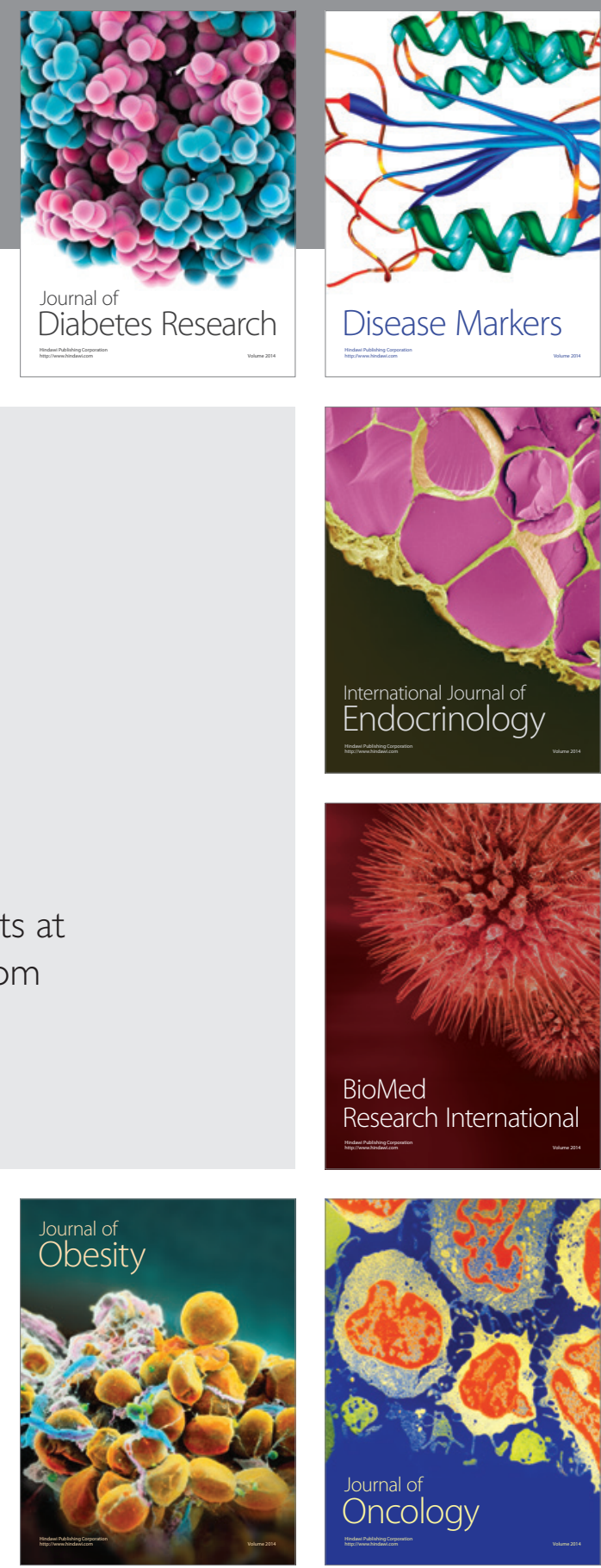

Disease Markers
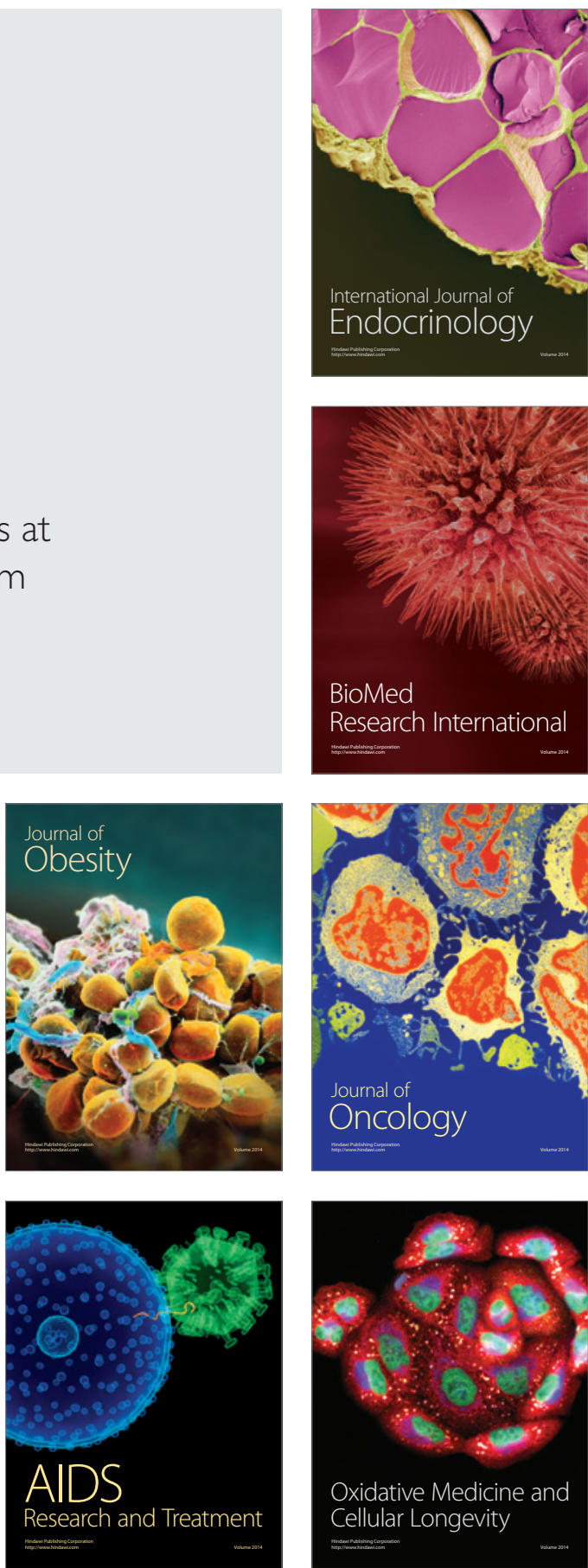